Check for updates

1 Sturm College of Law, University of Denver

2 Massachusetts Institute of Technology (MIT)

3 Boston College

Cite this as: $B M J 2022 ; 376: 0276$ http://dx.doi.org/10.1136/bmj.0276 Published: 01 February 2022

\section{Fair access to scarce medical capacity for non-covid-19 patients: a role for reserves}

\author{
Govind Persad, ${ }^{1}$ Parag A. Pathak, ${ }^{2}$ Tayfun Sönmez, ${ }^{3}$ M. Utku Ünver ${ }^{3}$
}

As hospitals in the US and elsewhere fill again with patients with covid-19, discussions about how to fairly allocate scarce medical resources have come to the fore once again. One frequently voiced concern is that non-covid-19 patients with urgent health needs are facing indefinitely postponed surgeries,

long-distance hospital transfers, or even are unable to access medical treatment. In our view, ${ }^{12}$ a reserve or categorised priority system could help. It could be used to fairly distribute scarce medical capacity-such as staffing, physical space, and medical treatments-between covid-19 and non-covid-19 patients, just as it has been used or proposed to allocate covid-19 therapeutics and vaccines. ${ }^{3-6}$

Before the covid-19 pandemic, some US states such as New York and Minnesota considered giving priority to health personnel in allocation guidelines for emergency ventilator scarcity, but became concerned that these essential personnel could occupy all the available ventilators in cases of extreme shortage..$^{8}$ These concerns about one population group taking up all of a scarce medical resource are a recognised problem with any sort of system that prioritises access based on a single factor, such as medical prognosis. A reserve or categorised priority system would prevent this outcome by assigning some subset of available resources to first be offered to specific groups-“reserve categories"-of patients. When a surge hits, a reserve system can prioritise non-covid-19 patients for access to a subset of resources, avoiding their being denied treatment or suffering from repeated delays in accessing needed procedures, while at the same time leaving many spots open to all patients, including those with severe covid-19.

This approach could be implemented as a non-covid-19 reserve category, which could be used to ensure a basic level of access to intensive care units or hospital beds, staffing, ECMO, dialysis, medications, or any other scarce medical resource. This reserve category would be a "minimum guaranteed reserve" that ensures that non-covid-19 patients always have priority access to a subset of beds (or another scarce resource) during surges. The remaining beds could be open to both covid and non-covid patients without further prioritisation, or a separate subset of beds could be considered as a minimum guaranteed reserve for covid patients.

How large should the non-covid-19 patient reserve be? This is not a technical decision, but an ethical one. But its size might be based, for instance, on the typical number of beds occupied by non-covid-19 patients before the pandemic. The decision ultimately depends on how hospital and community decisionmakers weigh the importance of preserving access for covid-19 as opposed to non-covid-19 patients. If desired, the size or eligibility criteria for the reserve could be adjusted depending on the severity of the emergency. Even in a severe crisis, the non-covid-19 reserve could allow hospitals to quickly decide which patients go where and guarantee a basic level of access to all patients, without having to categorically exclude some groups of seriously ill patients whose needs are judged insufficiently urgent.

To protect access to medical services during surges of hospitalised unvaccinated covid-19 patients, some have instead advocated using vaccination status as a factor or a tiebreaker. ${ }^{9}$ A non-covid-19 reserve is not based on vaccination status, avoiding legal problems in jurisdictions where considering vaccination status is prohibited, ${ }^{10}$ and not presenting the ethical problems some have raised regarding the use of vaccination status in triage. ${ }^{11}$ Creating a non-covid-19 patient reserve would also allow hospitals to use specific allocation rules for distributing among covid-19 patients and patients without covid-19 respectively, while reducing the need for cross-condition comparisons (e.g., comparing patients on routine dialysis to covid-19 patients in need of acute dialysis).

While prioritising a portion of scarce treatments for non-covid-19 patients neither explicitly penalises unvaccinated patients nor rewards vaccinated ones, the latter group can be expected to benefit more from this policy. This is because vaccines' powerful protection against severe covid-19 implies that, statistically, vaccinated people are likely to comprise a larger share of patients needing scarce medical treatment for reasons other than covid-19 than of patients needing scarce treatment for severe covid-19 infection.

In the face of covid-19 pressures on hospital capacity, a reserve system can help realise the socially valued goal of ensuring that pandemic response does not overwhelm all other medical aims and values. It is worth incorporating in many settings where decisionmakers fear that covid-19 patients will overwhelm hospital capacity. Formalising reserve categories can also help reduce the need to downgrade all care to a "contingency" level, a step which often has disproportionately bad effects on patients from minority groups experiencing discrimination and people who have serious preexisting conditions. ${ }^{12}$ If needed, a reserve system would enable the portion of scarce capacity not prioritised for non-covid-19 patients to operate at a contingency or crisis level, while the reserved portion could be effectively firewalled from the capacity pressures caused by covid-19 surges. When hospitals face ongoing surges, a reserve that protects capacity 


\section{OPINION}

for non-covid patients could be crucial to successfully and fairly managing limited resources.

Competing interests: GP reported receiving grants from Greenwall Foundation and personal fees from ASCO Post and the World Health Organisation outside the submitted work. None further declared.

1 Pathak PA, Sönmez T, Ünver MU, et al. Fair allocation of vaccines, ventilators and antiviral treatments: leaving no ethical value behind in health care rationing. In Proceedings of the $22 \mathrm{nd}$ ACM Conference on Economics and Computation 2021 Jul 18 (pp. 785-786).

2 Sönmez T, Pathak PA, Ünver MU, Persad G, Truog RD, White DB. Categorized priority systems: A new tool for fairly allocating scarce medical resources in the face of profound social inequities. Chest 2021;159:1294-9.pmid: 33373597

3 Rubin E, Dryden-Peterson SL, Hammond SP, etal. A novel approach to equitable distribution of scarce therapeutics: institutional experience implementing a reserve system for allocation of COVID-19 monoclonal antibodies. Chest 2021;160:2324-31.pmid: 34371010

4 California Office of the Governor. California Leads with Public Health and Vaccine Equity to Safely and Sustainably Reopen | California Governor. 2021. https://www.gov.ca.gov/2021/03/04/california-leads-with-public-health-and-vaccine-equity-to-safely-and-sustainably-reopen/

5 Tennessee Department of Health. Interim covid-19 Vaccination Plan. 2020. Centers for Disease Control and Prevention. https://www.cdc.gov/vaccines/covid-19/downloads/tennessee-jurisdictionexecutive-summary.pdf

6 Schmidt H, Pathak P, Sönmez T, Ünver MU. Covid-19: how to prioritize worse-off populations in allocating safe and effective vaccines. BM/2020;371:m3795. doi: 10.1136/bmj.m3795. pmid: 33020072

7 Zucker H, Adler K, Berens D, et al. Ventilator Allocation Guidelines. New York State Task Force on Life and the Law, New York Department of Health. 2015. https://www.health.ny.gov/regulations/task_force/reports_publications/docs/ventilator_guidelines.pdf

8 Vawter D, Garrett J, Gervais K, et al, For the Good of Us All. Ethically Rationing Health Resources in Minnesota in a Severe Influenza Pandemic. Minnesota Pandemic Ethics Project, Minnesota Department of Health. https://www.health.state.mn.us/communities/ep/surge/crisis/ethics.pdf

9 Brown T. Of course hospitals in crisis mode should consider vaccination status. Washington Post. 2021. https://www.washingtonpost.com/opinions/2021/09/23/hospitals-ration-covid-vaccinationstatus/

10 Sparks S. How 'Vaccine Discrimination' Laws Make It Harder for Schools to Limit COVID Spread. EducationWeek. 2021. https://www.edweek.org/leadership/how-vaccine-discrimination-lawsmake-it-harder-for-schools-to-limit-covid-spread/2021/09

11 Wikler D. When medical care must be rationed, should vaccination status count? Washington Post. 2021. https://www.washingtonpost.com/outlook/2021/08/23/refuse-covid-treatment-unvaccinated-triage/

12 Hsia RY, Sarkar N, Shen YC. Impact of ambulance diversion: black patients with acute myocardial infarction had higher mortality than whites. Health Aff (Millwood) 2017;36:1070-7.pmid: 28583966 